\title{
BEARING CAPACITY OF FOLDED PLATE FOUNDATIONS IN CLAY SOIL
}

\section{Yakni Idris}

Universitas Sriwijaya, Faculty

of Engineering, Civil

Engineering Departement,

Palembang, Indonesia

\author{
Ratna Dewi \\ Universitas Sriwijaya, Faculty \\ of Engineering, Civil \\ Engineering Departement, \\ Palembang, Indonesia
}

\author{
Yulindasari Sutejo \\ Universitas Sriwijaya, Faculty \\ of Engineering, Civil \\ Engineering Departement, \\ Palembang, Indonesia
}
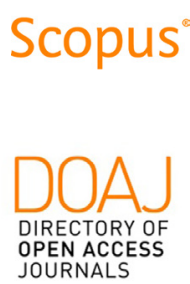

Crossref

$R \partial A D \equiv$

\section{Said Agil Al Munawar}

Universitas Sriwijaya, Faculty

of Engineering, Civil

Engineering Departement,

Palembang, Indonesia

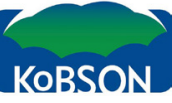

Key words: modified flat foundation, clay, shell foundation, settlement factor doi:10.5937/jaes0-30475

Cite article:

Online aceess of full paper is available at: www.engineeringscience.rs/browse-issues 


\title{
BEARING CAPACITY OF FOLDED PLATE FOUNDATIONS IN CLAY SOIL
}

\author{
Yakni Idris, Ratna Dewi*, Yulindasari Sutejo, Said Agil Al Munawar \\ Universitas Sriwijaya, Faculty of Engineering, Civil Engineering Departement, Palembang, Indonesia
}

The design of a foundation is inseparable from the type and strength of the soil, for example, soft or medium clay soils have poor properties for structures due to their low bearing capacity. Therefore, it is necessary to modify the model of a foundation to increase its bearing capacity and one of the popular methods is the application of folded plate on a flat foundation with angles and flange lengths on both sides. Therefore, this research presented its application at different flange lengths of $0.5 B, 0.75 B, 1 B, 1.25 B$, and $1.5 B$ where $B$ is the width of the flat plate and the results showed the bearing capacity of the folded plate was higher than the flat foundation. Moreover, an increment in the folded length led to a bigger ultimate load and smaller settlement but the ultimate load and settlement were observed to be almost constant at over $1 B$. This means the optimum variation where the flange length is equal to the foundation width is $1 B$ and it was observed to have increased by $129.52 \%$ using the Tangent Method and $148.47 \%$ with Butler Hoy Method. Meanwhile, the lowest settlement factor for the folded plate foundation was 0.22 with the highest bearing capacity of $61.19 \mathrm{kN} / \mathrm{m}^{2}$

Key words: modified flat foundation, clay, shell foundation, settlement factor

\section{INTRODUCTION}

The type of foundation to be used in construction is usually adjusted to the type and load of the building and the surrounding soil. For example, the distribution of a greater load in shallow foundations leads to an increase in the size, thereby, making its use for larger loads less practi$\mathrm{cal}$ and efficient. Therefore, folded plate structures which are previously used in roof structures have become an important focus of research to be used as an alternative method of modifying flat foundations.

Previous studies conducted on the modification of flat and shell foundations have shown the possibility of improving their performance based on load capacity and impairment characteristics. Different forms of shell foundations such as triangular [1], [2] and [3], hyper or hyperbolic [4], and [5], conical and pyramidal shell [6] and [7] were used to experimentally and numerically study the geotechnical behavior of the foundation in sandy soils.

Triangular shell strip foundation was modeled by Hanna, et al [1] with peak angles of $600,900,1200,1500$, and 1800 of the flat footings. The footing strip was placed on homogeneous sand and results showed the ultimate bearing capacity of the triangular shell strip foundation provides a higher bearing capacity and results in less settlement when compared to conventional flat foundations.

Kurian, N.P et al [5] also modeled three shell foundation configurations which are conical, spherical, and hyperbolic paraboloidal and the results showed the advantages of the shell foundation. The upright conical shells were subjected to vertical and horizontal loads and the moments required $86 \%$ lesser load in comparison with the use of only vertical loads. The load was, however, 45 $\%$ higher than the plain circular footing imposed on the same load.
There was also an examination of two types of shells foundation which are conical and pyramidal with axisymmetric and three-dimensional conditions using the numerical finite element program PLAXIS-2D [6] and the ultimate bearing capacity of these two types was found to be higher than the footplate foundation.

The bearing capacity of folded plate foundations on colored and colorless dry sandy soil was analyzed using a cone shape with three angular variations by Colmenares J.E [7] and sand was considered to be the representative of the characteristics which is easy to produce the same attributes with the conditions in each test in comparison with the clay to ensure the data obtained was more accurate.

Hanna and Abdel-Rahman [8] also investigated the bearing capacity and settlement of conical, triangular, and pyramidal shells in comparison with the flat and square circular shapes under plane strain conditions and an increase of $40 \%$ was recorded in the bearing capacity for the $60^{\circ}$ peak angle of the flat model.

These explanations, therefore, led to the focus of this research on the square shape of the folded plate foundation with different embedded plate or foundation foot dimensions in order to determine its effect on bearing capacity and settlement in clay soil. A flat foundation was modified with the addition of several flange lengths on the left and right at an angle to the footplate foundation to increase its bearing capacity.

Shell foundation was applied on sandy soil to determine the bearing capacity of the sand soil using angular variations of $60^{\circ}, 90^{\circ}, 120^{\circ}, 150^{\circ}$, and $180^{\circ}$ and the smallest ultimate value was found at $180^{\circ}$ which is for a flat foundation. A smaller shell angle leads to a greater bearing 
capacity for the foundation and this means those with a shell have higher values compared to those without a shell [1]. Moreover, folded foundations have been studied by El-Kady (2017) to determine their performance at different angles of $0^{\circ}, 10^{\circ}, 20^{\circ}, 30^{\circ}$, and $40^{\circ}$ and the most effective was found to be $30^{\circ}$ while the smallest decrease was observed in a folded foundation compared to a flat foundation and the maximum tensile stress also reduced by $48 \%$ [9].

The design of a folded plate foundation can be planned by calculating the shell foundation and the possible independent ways are shown in Figure 1 at different load distribution conditions. These two methods are required due to the two interpretations of the direction of the ground pressure.

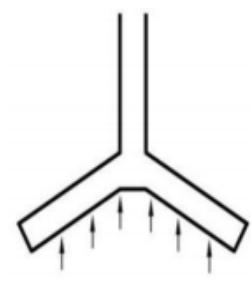

(a)

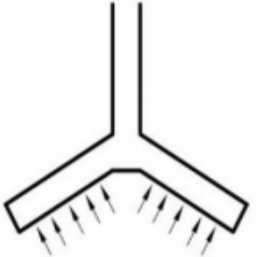

(b)
Figure 1: The load direction on the foundation (a) Load distributed vertically and evenly in the direction of the z-axis and (b) The load is normally distributed to the shell surface foundation [10].

The shell foundation theory also applies to the folded plate foundations which states that a foundation with the ability to withstand the loads evenly distributed without causing considerable damage or other deflection effects can be used as a footplate foundation on the ground with low bearing capacity. Moreover, the effects of moment and shear are negligible and the membrane theory is also sufficient for shells with multiple bends.

\section{Ultimate load determination}

The load-settlement graph produced from the loading test determines the ultimate load while the Tangent and Buttler Hoy methods were used in interpreting the curve. In the Tangent method, the ultimate bearing capacity of the foundation is determined by drawing the first tangent to the beginning and end of the load-settlement curve. The intersection of these two tangents is assumed to represent the ultimate bearing capacity of the foundation [11].

Another method to determine the ultimate method is the Buttler and Hoy and it involves using a tangent with an angle of $0.127 \mathrm{~mm} / \mathrm{kN}$ on the load-settlement curve and has been observed to be applied by Olgun et al. (2018) in interpreting pile load test in the field using the line located tangent to the end curve and another tangent drawn through the base of the load-settlement curve and the intersection of these two were used to produce the ultimate load from the loading test results [12] as shown in Figure 2.

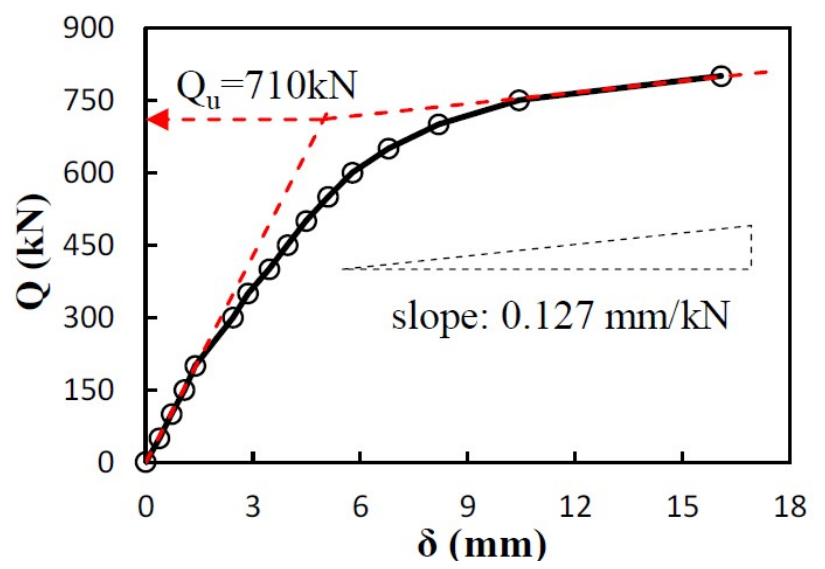

Figure 2: Ultimate load determination of the Buttler Hoy Method

\section{Bearing capacity efficiency factor}

Folded plate foundations act as the load-bearing platform in soft soils and it is possible to increase their ultimate bearing capacities with those observed in flat foundations which are generally calculated through the shell foundation. Meanwhile, the efficiency factor is the ratio of the difference between the increase in the ultimate bearing capacity of the two foundations as shown in the following equation [2].

$\eta=\frac{Q_{u s}-Q_{u f}}{Q_{u f}}$

where;

$\eta=$ Efficiency factor

Qus=The ultimate load of the folded plate foundation

Quf=The ultimate load of the footplate foundation

Meanwhile, the settlement characteristics of a folded plate foundation in comparison with a conventional flat foundation were analyzed using a non-dimensional settlement factor $\left(F_{\delta}\right)$ which was calculated at the ultimate load to reflect the characteristics of the foundation during the loading process [2]. The settlement factor is, therefore, presented in equations (2).

$F_{\delta}=\frac{\delta_{u} Y A_{b}}{P_{u}}$

where:

$\delta u=s e t t l e m e n t$ in ultimate load

$\mathrm{Y}=$ soil unit weight

$A b=$ the cross-sectional area of the foundation in a horizontal projection

$\mathrm{Pu}=$ ultimate foundation load

\section{MATERIALS AND METHODS}

The folded plate foundations modeling was presented in this study to increase the bearing capacity of flat foundations in clay soil at a laboratory scale. The disturbed soil samples used were obtained from the quarry area in Seriguna Village, Pedamaran, Ogan Komering Ilir Re- 


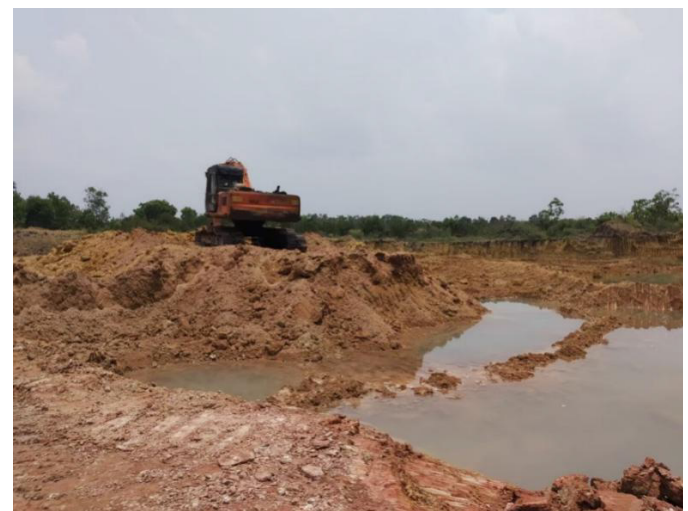

Figure 3: Soil conditions where the samples were obtained

gency, South Sumatra with the samples found to be in the field conditions shown in Figure 3.

\section{Soil properties}

The property index of the soil tested includes the moisture content, specific gravity, soil unit weight, and grainsize analysis and the results are presented in the following table.

Table 1: Soil properties index

\begin{tabular}{|c|c|}
\hline Index Properties & Value \\
\hline Moisture content (average) & $36 \%$ \\
\hline Specific gravity & 2.60 \\
\hline Unit weight & $16.5 \mathrm{kN} / \mathrm{m}^{3}$ \\
Liquid limit & $97 \%$ \\
Plastic limit & $41.88 \%$ \\
Plasticity index & $55.12 \%$ \\
Passing sieve No. 40 & $98.06 \%$ \\
Passing sieve No. 200 & $95.09 \%$ \\
Soil type & $\mathrm{CH}$ \\
\hline
\end{tabular}

The soil moisture content was determined before the loading test with each sample expected to have $\pm 36 \%$, the specific gravity obtained in the laboratory was 2.60 while the unit weight was $16.5 \mathrm{kN} / \mathrm{m}^{3}$.

The sieve analysis test was conducted to determine the percentage of soil which passes the sieve at each filter size, especially numbers 40 and 200 and the results showed $98.06 \%$ and $95,09 \%$ passed through the sieves respectively.

While the percentage of soil grains gradation based on both sieve and hydrometer analyses were $5 \%, 57 \%$, and $38 \%$ for sand, silt, and clay respectively and Atterberg limit value as shown in the results are plotted in the unified soil classification system in the form of $\mathrm{CH}$ (High Plasticity Clay).

\section{The folded plate foundation model}

Engineering properties of folded plate foundation are the unit weight of material $76,98 \mathrm{kN} / \mathrm{m}^{3}$ and elasticity modulus $2 \times 108 \mathrm{kN} / \mathrm{m}^{2}$.
The folded plate foundation was modeled through the addition of flanges on both sides with different lengths. Moreover, the foundation model used was according to Azzam et al. [2] which involves using steel plates with an average thickness of 3 to $20 \mathrm{~mm}$ with $8 \mathrm{~mm}$ applied in this study as shown in the geometry of the folded plate foundation model presented in Figure 4 with the width, B, observed to be $15 \mathrm{~cm}$ while the flange length, $H$, was varied between, 0.5B, 0.75B, 1B, 1.25B and 1.5B as shown in Figure 5. The choice of 120-degree angle was based on the reason that before testing the variation in flange length, the variation in flange angle was also tested and the result was that 120-degree was the optimum angle.

The properties index of the clay soil was determined and it was placed in a test tube of $75 \mathrm{~cm}$ height without being compacted or any additional water to ensure it has conditions considered to be very close to the original obtained from the field. Furthermore, the tub was covered with plastic and silenced for 24 hours to ensure the moisture content and shear strength are the same in each test before the vane shear was tested while the loading test was conducted according to the ASTM standard number

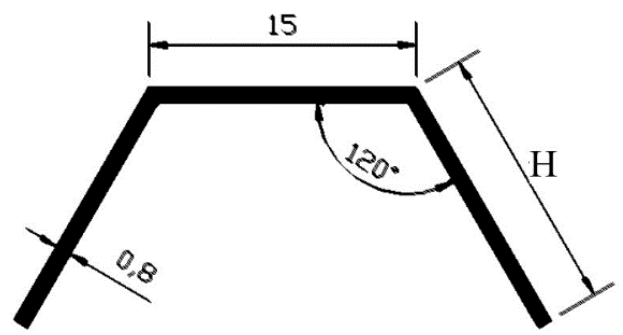

Figure 4: Schematic diagram of the folded plate foundation model
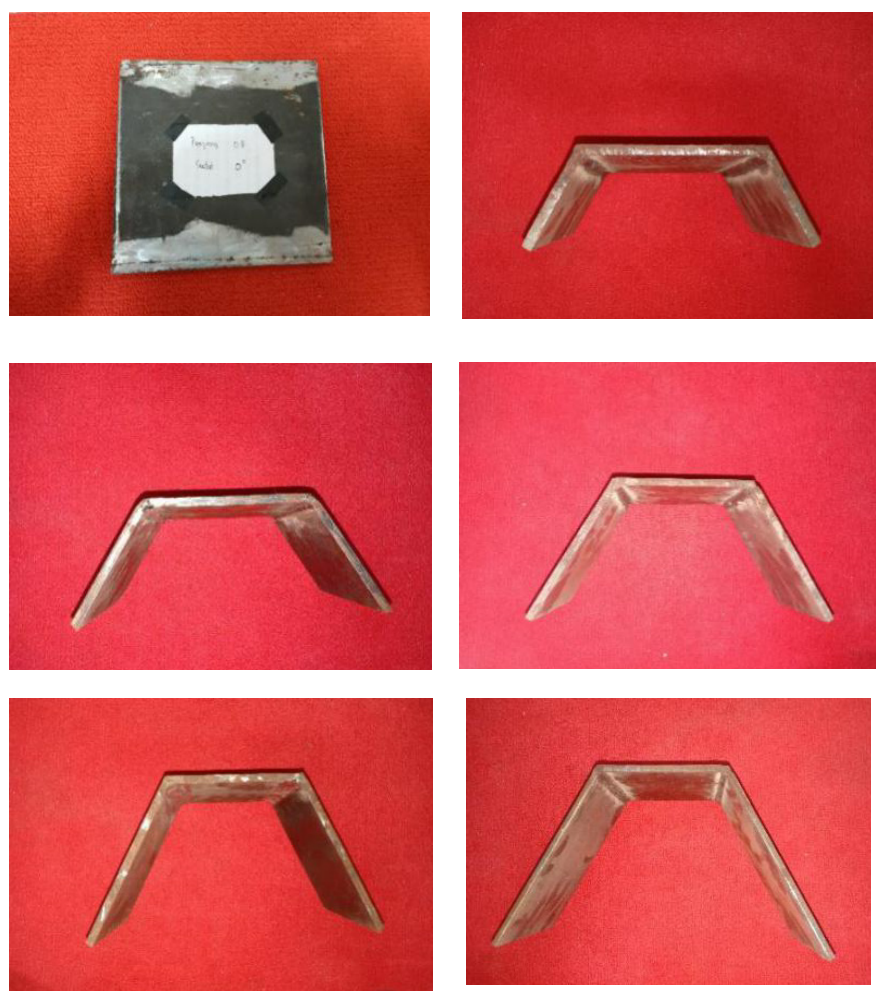

Figure 5: Folded plate foundation variation model 


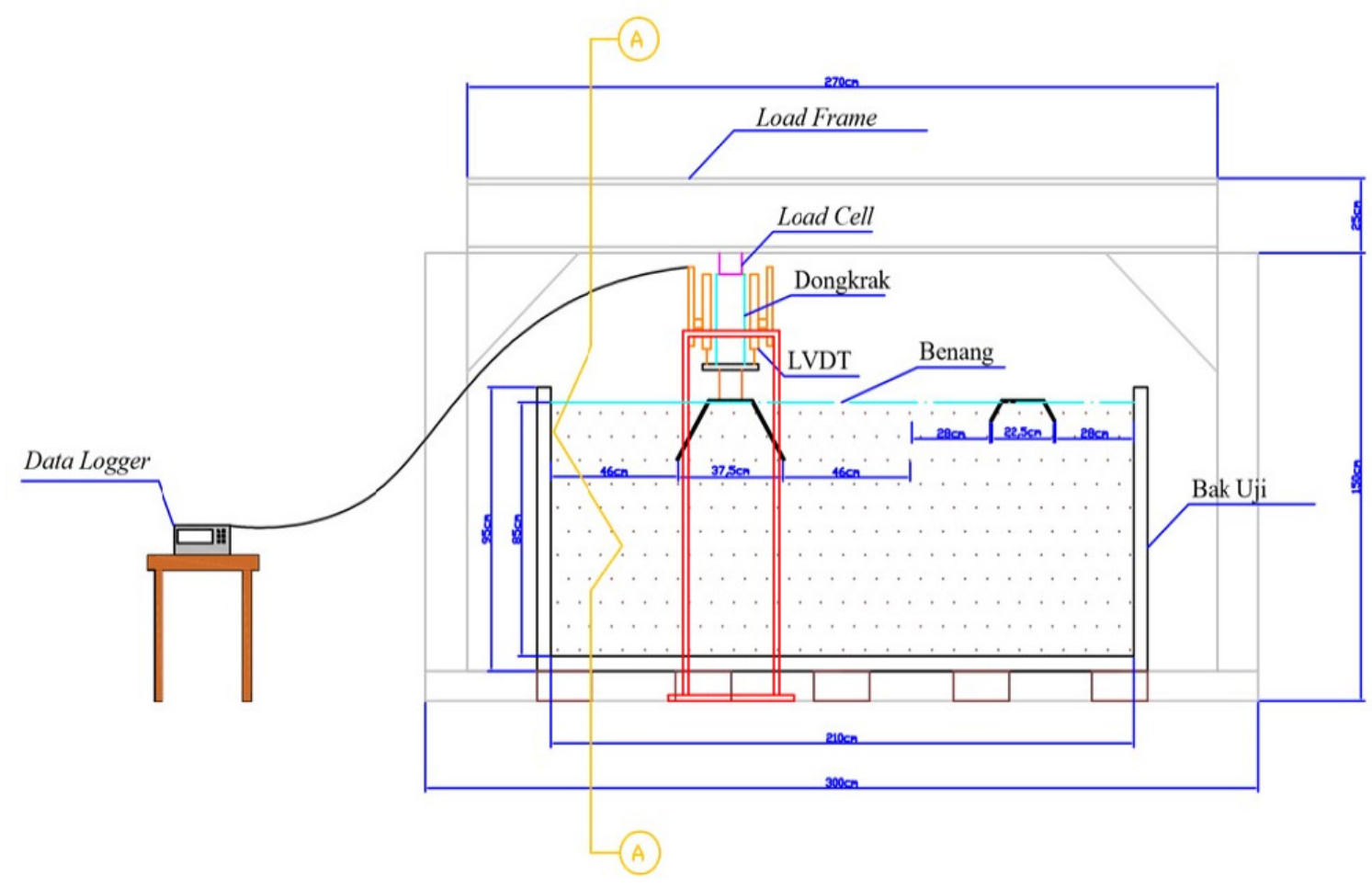

Figure 6: Schematic diagram of foundation loading modeling

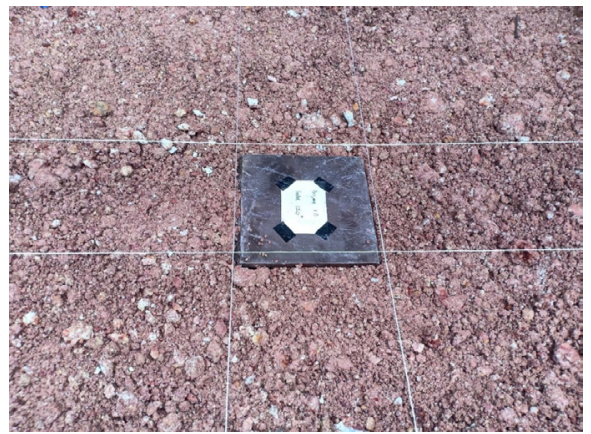

Figure 7: Position of the foundation before testing

D-1194 using a load at $5 \%$ of the ultimate bearing capacity of the plan which is $0.1 \mathrm{kN}$ for 5 minutes. This process was continued with an addition of $0.1 \mathrm{kN}$ until the foundation collapses and the loading test results were interpreted using the Butler Hoy and Tangen method graphs after which the qu value or the bearing capacity was obtained.

The foundation model was tested in a test tube with 2.1 $\mathrm{m} \times 1 \mathrm{~m} \times 1 \mathrm{~m}$ dimension and illustrated as indicated in Figure 6 . Folded plates are placed in the test box under the reference lines that have been installed. The folded plate is installed until the bottom of the flat plate reaches the ground level. As shown in Figure 7.

\section{RESULTS AND DISCUSSION}

\section{Flat and folded plate foundations}

The loading test results were obtained from the data logger which was directly inputted into the graph of the relationship between settlement and load and later interpreted using the Butler Hoy and Tangent methods to determine the ultimate load as shown in Figure 8.
Figure 8 shows the ultimate loads obtained for the footplate using the two methods are almost the same as observed from the $0.54 \mathrm{kN}$ from the Tangent Method and $0.58 \mathrm{kN}$ from the Butler Hoy method. Moreover, the loading results of the folded plate foundation based on the different flange lengths are presented in the load and settlement relationship graph of Figure 9 and the load applied to the foundation was observed to have caused an increment in the collapse based on the length of the flanges.

Table 2 shows the value of the ultimate load obtained from the load-settlement graph using both Butler Hoy and Tangent methods for each flange length variation and increment was observed with an increase in the flange length up to $1 \mathrm{~B}$ while higher values were found to be close to constant. This is indicated in the closeness of $1.25 \mathrm{~B}$ and $1.5 \mathrm{~B}$ on the graph which led to the production of almost the same value for the ultimate load.

The results presented in the table are the same as those presented in previous studies [13], [14] and the settlement of folded plate foundations found to be lower than flat foundations. Moreover, a longer fold leads to more decrease and this means the length of the flanges has the ability to reduce the settlement occurring in the foundation and the same was observed with the ultimate load value in line with the flange length but the magnitude of the decline became constant after 1B. Meanwhile, the ultimate load value obtained was used to determine the bearing capacity of each foundation as indicated in Figure 10.

Figure 10 shows both methods provide the same tendency even though Butler Hoy usually has a higher qu value compared to the Tangent method. The graph fur- 


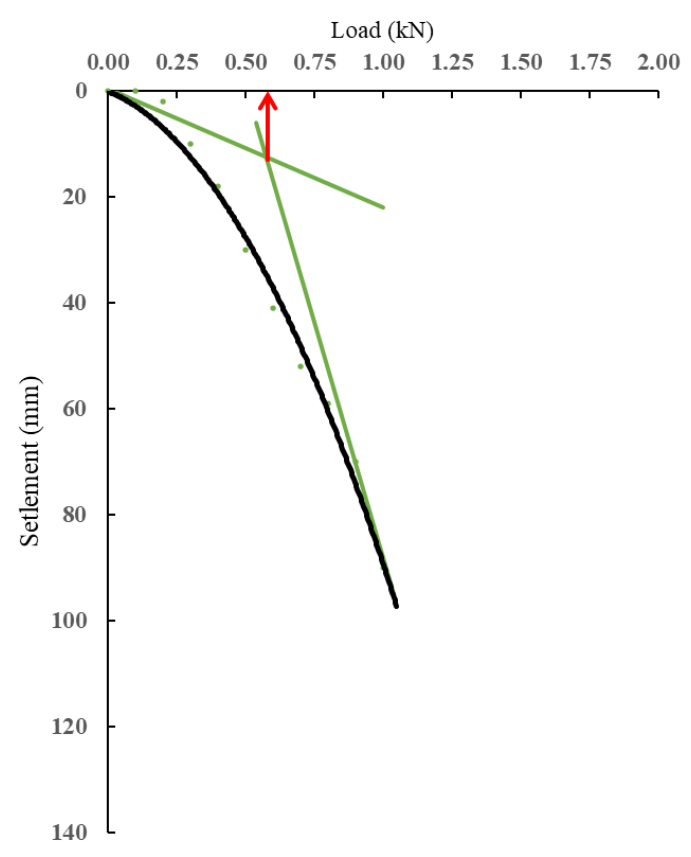

(a)

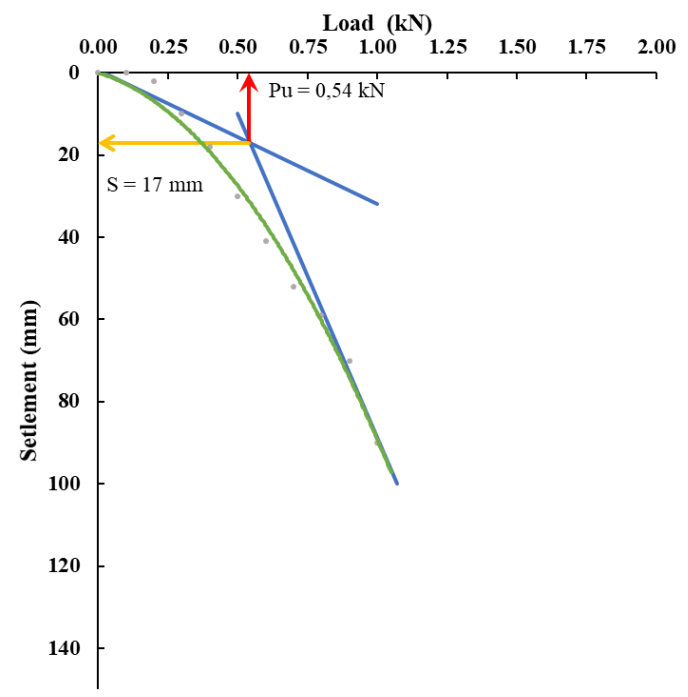

(b)

Figure 8: Graph of load and settlement for flat footing

Table 2: Pu value and folded plate foundation settlement

\begin{tabular}{|c|c|c|c|}
\hline \multirow{2}{*}{$\begin{array}{c}\text { Flange } \\
\text { Length } \\
\text { Variation }\end{array}$} & \multicolumn{2}{|c|}{ Pu value $(\mathrm{kN})$} & \multirow[b]{2}{*}{$\begin{array}{l}\text { Settlement } \\
\quad(\mathrm{mm})\end{array}$} \\
\hline & $\begin{array}{l}\text { Tangent } \\
\text { Method }\end{array}$ & $\begin{array}{c}\text { Butler Hoy } \\
\text { Method }\end{array}$ & \\
\hline Flat footing & 0.54 & 0.58 & 17 \\
\hline $0.5 \mathrm{~B}$ & 1.01 & 1.15 & 16 \\
\hline $0.75 \mathrm{~B}$ & 1.7 & 1.89 & 15 \\
\hline $1 \mathrm{~B}$ & 2.5 & 2.71 & 11.5 \\
\hline $1.25 \mathrm{~B}$ & 2.68 & 2.73 & 7 \\
\hline $1.5 \mathrm{~B}$ & 2.81 & 2.85 & 7 \\
\hline
\end{tabular}

ther indicates the increase in the ultimate bearing capacity of each variation to the bearing capacity of the site foundation while the optimum length of the flange was

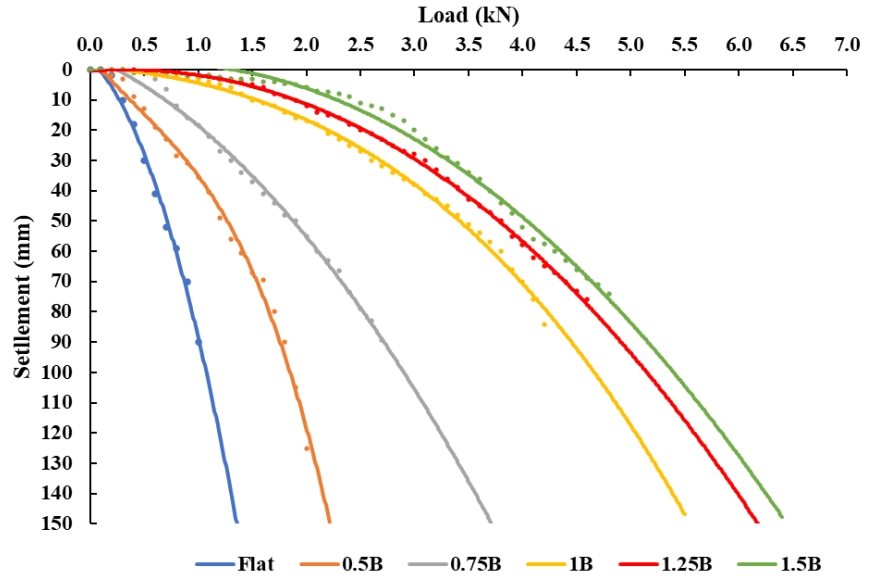

Figure 9: Graph of load and settlement relationship of folded plate foundations with different flange lengths

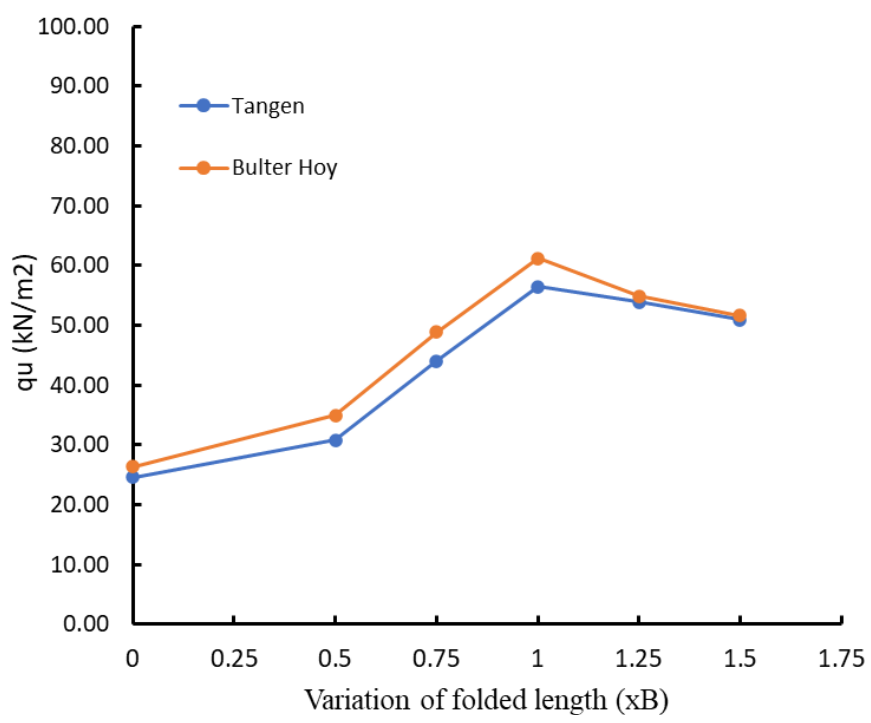

Figure 10: The qu value in each flange length variation

obtained when $\mathrm{H}=\mathrm{B}$ and this was used to determine the maximum bearing capacity. This is associated with the constant ultimate load observed with the flange length variations which are more than $1 \mathrm{~B}$ while the horizontal projection area of the foundation was getting bigger and this causes the bearing capacity of the area to reduce. This, therefore, means the lengths added are no longer effective when they are more than the width of the flat foundation. Meanwhile, the highest possible bearing capacity obtained for the folded plate foundation was found to be $61.19 \mathrm{kN} / \mathrm{m}^{2}$.

The difference in the increase between the bearing capacities of the folded plate and $\eta_{\mathrm{PT}}$ foundations was obtained using the following equation [2]:

$\eta_{p t}=\frac{\left(Q U_{s}-Q U_{f}\right)}{Q U_{f}} \times 100 \%$

where:

$\eta_{\mathrm{PT}}=$ Percentage increase in bearing capacity of the flat foundation

Qus=bearing capacities of the folded plate

Quf=bearing capacities of the flat foundation 
Table 3: The difference in qu value increase in each flange length variation

\begin{tabular}{|c|c|c|c|c|c|}
\hline \multirow{2}{*}{ Flange length variation } & \multicolumn{2}{|c|}{ Tangent Method } & \multicolumn{2}{|c|}{ Butler Hoy Method } & \multirow{2}{*}{ Settlement Factor $F_{\delta}$} \\
\hline & $\eta_{\mathrm{PT}}{ }^{*}$ & $\eta_{P F}^{* *}$ & $\eta_{\mathrm{PT}}{ }^{*}$ & $\eta_{P F}^{* *}$ & \\
\hline Flat footing & - & - & - & - & 1.17 \\
\hline $0.5 \mathrm{~B}$ & $25.12 \%$ & - & $41.96 \%$ & - & 0.88 \\
\hline $0.75 B$ & $78.77 \%$ & $42.88 \%$ & $98.36 \%$ & $39.73 \%$ & 0.57 \\
\hline 1B & $129.52 \%$ & $28.39 \%$ & $148.47 \%$ & $25.26 \%$ & 0.34 \\
\hline $1.25 \mathrm{~B}$ & $118.84 \%$ & $-4.65 \%$ & $122.85 \%$ & $-10.31 \%$ & 0.22 \\
\hline $1.5 \mathrm{~B}$ & $107.00 \%$ & $-5.41 \%$ & $109.89 \%$ & $-5.82 \%$ & 0.23 \\
\hline
\end{tabular}

$\eta_{p t}=\frac{(30,81-24,63) \mathrm{kN} / \mathrm{m}^{2}}{24,63 \mathrm{kN} / \mathrm{m}^{2}} \times 100 \%=25,12 \%$

The settlement characteristics at the ultimate load are determined based on the values presented in Table 3 and reduction was generally observed for each variation in the folded plate foundation with the longer folded length. The comparison between the two types of foundations shows the folded plate has a lower settlement factor and this indicates better characteristics but a small increase was observed in the factor at $\mathrm{H}=1.5 \mathrm{~B}$. Moreover, the factor's reduction in the folded plate foundation in comparison with the maximum flat foundation was found to be $81 \%$ and this further confirms the effectiveness of the folded plate foundation in controlling vertical settlement.

\section{CONCLUSIONS}

The folded plate foundation loading was tested and some of the conclusions drawn include the following:

1. The addition of flange length on the flat foundation significantly caused an increase in the bearing capacity as observed from the greater values recorded for the folded plate foundation in comparison with the tread foundation and the greatest increase of 129.52 $\%$ was found using the Tangent Method while 148.47 $\%$ was produced by Butler Hoy Method. Moreover, the optimum variation was observed to be $1 \mathrm{~B}$ as indicated with the decline in the bearing capacity after this mark. Therefore, it can be stated that the foundation with a flange length which exceeds the footplate width is no longer optimal.

2. The settlement of the flat foundation was, however, observed to be greater than the folded plate foundation and the variations of the flange length for the folded plate foundation at the same angle showed the longer flange produced the smaller reduction in the settlement with the lowest found in $1.25 \mathrm{~B}$ recorded to be $7 \mathrm{~mm}$ at a reduction factor of 0.22 .

3. The foundation material used in this study is steel, for further research, concrete can be used as the material.

\section{ACKNOWLEDGEMENTS}

The author appreciates the Universitas Sriwijaya Research and Community Service Institute for supporting this research to ensure proper completion.

\section{REFERENCES}

1. A. Hanna and M. A. El-Rahman. (1990). Ultimate bearing capacity of triangular shell strip footings on sand. Journal of Geotechnical Engineering., vol. 116, no. 12, 1851-1863, doi: 10.1061/(ASCE)07339410(1990)116:12(1851).

2. W. R. Azzam and A. M. Nasr. (2015). Bearing capacity of shell strip footing on reinforced sand. Journal of Advanced Research, vol. 6, no. 5, 727-737, doi: 10.1016/j.jare.2014.04.003.

3. R. Rinaldi, M. Abdel-Rahman, and A. Hanna. (2018). Experimental Investigation on Shell Footing Models Employing High-Performance Concrete. Facing the Challenges in Structural Engineering. GeoMEast 2017, p. 373-390, doi: 10.1007/978-3-319-619149_29.

4. B. B. K. Huat and T. A. Mohammed. (2006). Finite Element Study Using FE Code (PLAXIS) on the Geotechnical Behavior of Shell Footings. Journal of Computer Science, vol. 2, no. 1, 104-108, doi: 10.3844/jcssp.2006.104.108.

5. N. P. Kurian and V. M. Jayakrishna Devaki. (2005). Analytical studies on the geotechnical performance of shell foundations. Canadian Geotechnical Journal, vol. 42, 562-573, doi: 10.1139/t04-110.

6. T. Lamya and M. K. Sheeja. (2021). Analytical Assessment on the Behaviour of Conical Shell Foundation. Proceedings of SECON 2020, p. 307-316, doi: 10.1007/978-3-030-55115-5_29.

7. J. E. Colmenares, S. R. Kang, Y. J. Shin, and J. H. Shin. (2014). Ultimate bearing capacity of conical shell foundations. Structural Engineering and Mechanics., vol. 52, no. 3, p. 507-523, doi: 10.12989/ sem.2014.52.3.507. 
8. A. Hanna and M. Abdel-Rahman. (1998). Experimental investigation of shell foundations on dry sand. Canadian Geotechnical Journal, vol. 35, no. 5, p. 847-857, doi: 10.1139/t98-049.

9. M. S. El-kady and E. F. Badrawi. (2017). Performance of isolated and folded footings. Journal of Computational Design and Engineering, vol. 4, no. 2, 150-157, doi: 10.1016/j.jcde.2016.09.001.

10. S. Timoshenko and S. Woinowsky-Krieger. (1959). Theory of Plates and Shells. New York: McGraw-Hill.

11. U.S. Army Corps of Engineers.(1991) Design of Pile Foundations. Engineering Manual 1110-2-2906. Washington, DC.
12. Y. Y. and A. H. M. Olgun. (2017). Interpreting Load-Settlement Curves of Pile Foundations by Graphical Methods. Eurasian Journal of Civil Engineering and Architecture, vol. 1, no. 1, p. 1-10.

13. T. Salem, N. R. N., El-Sakhawy, and A. A. El-Latief. (2021). Experimental and numerical study for the optimization of bottom of foundation shapes on soft soils. Innovative Infrastructure Solutions, vol. 6, no. 2, doi: 10.1007/s41062-021-00455-7.

14. S. Thilakan and N. P. Naik. (2016). Geotechnical Behaviour of Strip Curved Shell. International Journal of Current Engineering and Science Research (IJCESR), vol. 3, no. 3, pp. 13-17. 